\title{
DISCUSSION PAPER
}

// KATRIN HUSSINGER AND JOÃO N. CARVALHO

The Long-Term Effect of Research Grants on the Scientific Output of University Professors 


\title{
The Long-Term Effect of Research Grants on the Scientific Output of University Professors
}

\author{
Katrin Hussinger ${ }^{1}$ and João N. Carvalho ${ }^{23}$ \\ This paper is forthcoming in Industry \& Innovation
}

September 2021

\begin{abstract}
A major source of research funding for university professors are competitive research grants. With focus on Luxembourg, we present results from a difference-in-difference analysis which show that research grants by the Luxembourg National Research Fund (FNR), the central research funding agency in Luxembourg, increase the scientific output of university professors by $31 \%$ which corresponds to one additional publication. We further show that the scientific output drops again around five years after the grant receipt. However, we find that those university professors who realize a quality increase of their journal publications in the years following the grant receipt benefit from a long-lasting publication quality effect.
\end{abstract}

Keywords: competitive research grants, university professors, scientific output, difference-indifference estimation

JEL classification: $\mathrm{I} 23, \mathrm{O} 38$

\footnotetext{
${ }^{1}$ Katrin Hussinger (corresponding author): University of Luxembourg, Faculty of Law, Economics and Finance, and ZEW - Leibniz Centre for European Economic Research.

6 Rue Richard Coudenhove-Kalergi, 1359 Luxembourg, Phone: +352-4666446404, Email: katrin.hussinger@uni.lu

${ }^{2}$ João N. Carvalho: Universidade NOVA de Lisboa, NOVA School of Business and Economics, Rua da Holanda n.1, 2775-405 Carcavelos, Lisboa, Portugal, Phone: +351968371295, Email: jpcnazario@gmail.com

${ }^{3}$ We would like to thank Benjamin Balsmeier and Maikel Pellens as well as the participants of the DEM department seminar at the University of Luxembourg for valuable discussion and comments as well as Kristian Kolev and Fjolla Sylla for research assistance.
} 


\section{INTRODUCTION}

The importance of basic research for technology development (Jaffe, 1989), industrial productivity growth (Adam, 1990) and the development of product and process innovations (Mansfield, 1991) is long understood as is the need for governmental intervention to finance basic research. Because of the long-term nature, the lack of immediate commercialization prospects, the risk of failure and of misappropriation of the results from private research by competitors firms tend to underinvest in basic research (Arrow, 1962, Salter and Martin, 2001). This is why basic research is largely conducted in the public sector and why basic research is financed to a large extent by governments.

While government financing of research and development (R\&D) activities in the public sector was traditionally distributed as institutional core funding to universities and public research institutes, competitive project funding has gained in importance as an additional, alternative research funding channel (Lepori et al., 2007, OECD, 2016). National public project funding as a percentage of government budget appropriations or outlays for R\&D (GBAORD) reached between 25.5\% (Austria) and 64.9\% (Ireland) for European countries in 2011 (OECD, 2018, p.14), which corresponds to an increase of $58 \%$ for Austria since 2000 and of $24 \%$ for Ireland since 2008, respectively. Competitive funding can be granted on the level of the institution, on the project and individual level.

Here, we provide empirical evidence for the impact of a project-based competitive research funding program for individual university professors on their scientific output. Therewith, we contribute to an increasing stream of literature that investigates the impact of research grant programs (Arora and Gambardella, 2005, Chudnovsky et al., 2008, Jacob and Lefgren, 2011, Azoulay et al., 2011, Benavente et al., 2012, Ganguli, 2017, Carayol and Lanoe, 2017, Ayoubi et 
al., 2019). Such programs exist in most developed countries and are governed in $89 \%$ of the OECD countries by national science agencies (OECD, 2018b, p. 208). Individual researchers affiliated with a national university or research institute can submit a grant proposal which is typically peer reviewed before a funding decision is taken. The research program designs vary only slightly across countries while the available research budget shows a greater heterogeneity (OECD, 2018b).

We focus on the largest program of project-based grants for individual researchers by the Luxembourg National Research Fund (FNR), the central research funding agency of Luxembourg. Using difference-in-difference (DiD) analysis, we present causal evidence for the impact of an individual grant on funded university professors' scientific output. The advantage of focusing on Luxembourg is that it has only one public university. In light of the finding that institutional factors have a major impact on researcher productivity (Stephan, 1996), this implies that all university professors, funded or not, face the exact same research conditions.

Our results show that a research grant increases the scientific publication output of the sponsored university professors by $31 \%$, which corresponds to a $62 \%$ increase for contributions to conference proceedings and a $20 \%$ increase for publications in scientific journals. Calculated differently, this corresponds to almost one additional publication or equivalently 0.5 additional publications in conference proceedings and 0.4 additional journal publications. The results are therewith in line with prior findings that suggest that a research grant leads to one or two additional publications (e.g. Gambardella and Arora, 2005, Jacob and Lefgren, 2011, Benavente et al., 2012). Our results hold for a variety of robustness checks. We further document that the funded professors' scientific output increase vanishes about five years after the grant receipt. We 
conclude that the project-based research funding for individual researchers of Luxembourg leads to a temporary research output increase for the average funded university professor.

In further analyses, we find that that those university professors who realize a quality increase of their journal publications, as measured by journal impact factors, in the years following the receipt of the grant, realize a long-lasting quality effect of their publications. This is an important finding as it suggests that the quality-enhancing effect induced by public funding can be lasting beyond the project duration and, hence, benefiting the individual researcher's future career, the university and society as higher quality research is taken out in the long run. In further investigations of observable characteristics that could potentially explain this effect such as career age, winning a grant for the first time or the amount of the granted funding, we miss to find robust evidence. Interviews with 10 randomly selected principal investigators suggest that the grants we are investigating are large (as compared to other available research grants) and hence allow some researchers to take a next step in their academic career. To the best of our knowledge, we are the first to document that there is a positive publication quality effect beyond the grant duration which does not depend not on observable researcher characteristics, but on the effectiveness with which some researchers use the grant, a factor which is difficult to access ex ante for funding agencies.

\section{LITERATURE}

Even though competitive research funding programs for individual researchers exist in most developed countries (OECD, 2018b), microeconomic evaluations are still relatively scarce (Arora and Gambardella, 2005, Chudnovsky et al., 2008, Jacob and Lefgren, 2011, Azoulay et al., 2011, Benavente et al., 2012, Ganguli, 2017, Carayol and Lanoe, 2017, Ayoubi et al., 2019). 
The existing studies focus on the determinants of receiving a grant as well as on the impact of research grants on the funded researchers' scientific output.

With focus on the likelihood of receiving a grant, previous studies find that the past publication output matters (Arora and Gambardella, 2005, Azoulay et al., 2011) as well as the past publication quality as measured by the journal impact factor (Ayoubi et al., 2019) or the number of prior top publications (Azoulay et al., 2011), the number of active grants (Ayoubi et al., 2019), gender (Azoulay et al., 2011) as well as having an affiliation with an elite university (Arora and Gambardella, 2005). This is in line with evidence from the policy side which concludes from a survey of different European grant programs that the track record of the applicant is of high importance (OECD, 2018, 2018b). Another important factor for the success of an application is the proposal itself (OECD, 2018). Here the scientific and societal impact are most important for most funding agencies (OECD, 2018b, Box 4.2). Unfortunately, only a few agencies use a score system to evaluate grant applications that could improve evaluation studies (Jacob and Lefgren, 2011, Ayoubi et al., 2019); and even where such scores exist, the scores are often not available to the evaluator.

With focus on the impact of research grants on scientific output, previous studies mostly find positive effects. The effect size varies. Arora and Gambardella (2005) focus on grant recipients at the U.S. National Science Foundation (NSF). They find that NSF grants have the largest impact for young scholars with a \$10,000 grant leading to one additional single-authored highquality paper. The reported effect for intermediate researchers is zero and slightly higher for more senior researchers. Using instrumental variables methods, Jacob and Lefgren (2011) report a small increase of $7 \%$, or one additional publication, for post doc researchers that receive a grant from the U.S. National Institute of Health (NIH). Lawson et al. (2021) do not find that 
competitive research funding is associated with a higher research productivity for researchers at the University of Turin.

A more optimistic estimate of a $15 \%$ increase in citation-weighted publications is reported by Carayol and Lanoe (2017) for the French national funding agency ANR (Agence Nationale de la Recherche). The results are based on a control group approach. Using a similar methodology, Chudnovsky et al. (2008) find that seven times the GDP per capita of Argentina would be needed as grant amount for a funded researcher receiving research funds from the Argentinian Fund for Scientific and Technological Research to produce an additional publication in a 5-years window. Benavente et al. (2012) find that research grants from the Chilean National Science and Technology Research Fund (FONDECYT) lead to two additional publications in the six years following the grant receipt. The result is based on a regression discontinuity analysis exploiting a discontinuity in grant eligibility criteria. Also relying on regression discontinuity analysis, Ganguli (2017) reports a large impact of a historical research grant program in the former Soviet Union. She concludes that the research grant doubled the productivity of the researcher at the margin. Another interesting finding by Ganguli (2017) is that grant recipients have a lower likelihood to leave academia.

In a recent study, Ayoubi et al. (2019) evaluate a Swiss funding program sponsoring interdisciplinary collaboration. Based on DiD results, they report that researchers who apply for the program experience an increase of $43 \%$ in publications and that their average impact factor increases by $7 \%$. Interestingly, whether the researcher receives the grant seems to have no additional effect on individual researcher scientific productivity.

With focus on different research grant program designs, Azoulay et al. (2011) compare a funding program that grants greater freedom to one that imposes more demands on the research of the 
grant recipient. Comparing the scientific work of investigators at the Howard Hughes Medical Institute (HHMI) which tolerates early failure and rewards long-term success with grantees from the NIH which face pre-defined deliverables and little tolerance of failure, Azoulay et al. (2011) conclude from a DiD analysis that the program that leaves the researcher with greater freedom leads to more high-impact articles and more novel research.

We contribute to the prior literature in two ways. First, we enrich the existing empirical evidence by investigating the effect of another research grant program. As program designs, funding amounts and the research landscapes vary, we believe that empirical evaluation results are difficult to generalize so that we need plenty of evidence to arrive at a better understanding of the effects of research funding programs. The heterogeneity of previous findings is in line with this argument. Second, we show that individual grants can have long lasting scientific quality effects. To the best of our knowledge, we are the first to document a heterogenous grant effect that depends not on observable researcher characteristics such as the career age, whether the applicant is a first-time grant winner or on the amount of funding, but on the effectiveness with which the researcher uses the grant which is not possible to be observed ex ante by funding agencies. This finding has important implications for funding agencies as well as for scientific organizations hosting grant recipients.

\section{INSTITUTIONAL BACKGROUND}

Luxembourg, one of the smallest European countries at the top of the European GDP per capita ranking, is also particular regarding its research landscape. The country hosts only one public university, the University of Luxembourg, which was established in 2003 and is financed by the 
state. Alongside exist public and private research institutes with different focus areas and missions.

Like most European countries, the public funding of research is governed by a national agency, the Luxembourg National Research Fund (FNR). Carrying the mission of setting up "a sustainable world-class research system [...] that will generate societal and economic impact in key strategic areas"4 its mission is comparable to other funding agencies like the U.S. National Science Foundation (NSF) or the German Research Foundation (DFG). The tying of research funding to "key strategic areas" defined by the government is also not uncommon and exists at around $25 \%$ of the European funding agencies (OECD, 2018b, Box 4.2).

The FNR's central program with an annual budget of about 20 million EUR between 2013 and 2018 is labelled CORE. It aims at "strengthen[ing] the scientific quality of Luxembourg's public research in priority research fields" (FNR, 2020, p.2). CORE targets individual researchers based in Luxembourg. It is a competitive and project-based funding program. CORE is only open to applications which target Luxembourg's national research priorities which are: Innovation in services, sustainable resource management in Luxembourg, new functional and intelligent materials and surfaces and new sensing applications, biomedical sciences/ regulation of chronic, degenerative and infectious diseases, labor market, education requirements and social protection, identities, diversity and integration and, lastly, societal challenges. The national research priorities changed slightly over time with a most recent and significant change in 2019 (FNR, 2019).

In the past, the University of Luxembourg was the major recipient of funding through CORE receiving slightly more than $40 \%$ of all granted projects. Most of the funded projects are

\footnotetext{
${ }^{4}$ https://www.fnr.lu/what-we-do/
} 
associated with the University of Luxembourg only, while a few are granted to partnerships between the University of Luxembourg and the national institutes. The University of Luxembourg also received the highest total amount of funding through CORE, around 145 million EUR, followed by the Centre de Recherche Public - Gabriel Lippmann which received about 114 million EUR. The large number of CORE projects and funding amount that the university receives is likely explained by the fact that Luxembourg has only one public university and that the University of Luxembourg is the only national institution that conducts research in all domains eligible for the CORE program.

CORE grant recipients at the University of Luxembourg report that the CORE program is a very important funding instrument because of the large amount of funding that can be acquired by an individual researcher through a single project application. Interviews with grant recipients that will be discussed in greater detail later in this paper show that university professors use the CORE grant to build or nurture a team of $\mathrm{PhD}$ students and post docs, to conduct experiments and to repair laboratory equipment. Interview partners agree that a CORE grant allows to conduct large-scale research projects that would not be possible without the grant.

The FNR aims to select projects for funding based on "excellence and quality in research" (FNR, 2018-2021, p.12). The project evaluation is done by "systematically submit[ting] funding requests to an assessment by independent international experts" (FNR, 2018-2021, p.12) and follows the "Principles for Scientific Merit Review" (Global summit on Merit Review, 2012). In practice, this corresponds to a peer review process where three international reviewers that are chosen based on their expertise in the respective research field (FNR, 2019). The evaluation of the proposals follows specific criteria, namely, the innovativeness of the idea and the scientific relevance, the appropriateness of the approach, the general feasibility of the project and the 
expected output and impact of the results (FNR, 2019). Therewith, the criteria are in line with those of most European funding agencies (OECD, 2018b, Box 4.2).

After having been awarded a CORE grant, researchers are required to report annually on the progress of the project concluding with a final report at the end of the project term. ${ }^{5}$ The annual reports require the grant holder to comment on the following criteria: major achievements in relation to the original project objectives and the scientific rationale; status of milestones and deliverables, deviations from the program plan, progress of $\mathrm{PhD}$ students (if applicable), cooperation with foreign partners, deviations from the budget; for junior applicants also the advancements of their career and mentoring. In addition, it is asked for electronic hard copies of publications and information about patents. The final report asks for summary information concerning the project next to a reassessment of the criteria of the annual reports. Electronic hard copies of publications and information about patents are to be included.

As compared to other European research grant programs, the CORE program has a relatively high success rate (Swedish Research Council, 2019). In 2018, the success rate for proposals received by the FNR was about $35 \%(F N R, 2018)$ and therewith slightly higher than the success rate at the DFG in Germany ${ }^{6}$ and lower than the high success rate of Switzerland of $45 \%$ (Ayoubi et al., 2019, for the SINERGIA grant program). In most countries such as Norway and the Netherlands the success rates are much lower with 23\% (The Research Council of Norway, 2018) and $14 \%$ respectively. ${ }^{7}$

\footnotetext{
${ }^{5}$ https://www.fnr.lu/funding-instruments/core/

${ }^{6} \mathrm{https} / / /$ www.dfg.de/en/dfg_profile/facts_figures/statistics/processing_times_success_rates/index.html

${ }^{7}$ https://www.nwo.nl/en/research-and-results/programmes/nwo/talent-scheme-/veni-awards-2019.html. The Dutch funding program for individual researchers has three tracks based on the career age of scientists. The number presented here refers to the VENI track for the most junior researchers in 2019.
} 


\section{DATA}

\section{University professors}

This project is based on a tailor-made dataset. We started with a list of all 230 assistant, associate and full professors that were employed at the University of Luxembourg as of October $31^{\text {st }} 2019$. The list of professors was made available to us by the human resource department of the University of Luxembourg. It contains the names of the professors, their position (assistant, associate or full professor) and their research unit. Additional information about the professors such as the date of their $\mathrm{PhD}$ and whether they received grants ( $>30.000$ EUR) in the past other than FNR grants was manually collected from the professors' CVs and homepages.

We focus on university professors only although the grant program is also open to researchers affiliated with Luxembourgish research institutes because the mission and research conditions of researchers at research institutes can differ significantly from those of university professors.

\section{Publications}

The university professor dataset was supplemented by publication records which were retrieved from the Web of Science (WoS). The WoS contains more than 34.502 scientific journals and conference proceedings. ${ }^{8}$ For some disciplines such as computer science and engineering where a speedy dissemination of research results is important contributions to conference proceedings can be of higher importance than journal publications, e.g. for the promotion and tenure decision of scientists (Patterson et al., 1999, Shamir, 2010). In total, the professors at the University of Luxembourg published 9803 studies over their entire career, 7616 of which are articles in

\footnotetext{
${ }^{8}$ https://clarivate.libguides.com/webofscienceplatform/coverage. The WoS also covers some books. However, the coverage of books is quite incomplete so that this information was not collected.
} 
scientific journals and 2187 contributions to conference proceedings. $47 \%$ of the total publications, which corresponds to $65 \%$ of the conference proceedings and $42 \%$ of the journal publications, are produced by professors that at some point in their career received a CORE grant. We use the sum of journal articles and proceedings (PUB), also journal articles (JOUR) and proceedings (PROC) separately, as well as co-author weighted journal articles (CJOUR) and proceedings (CPROC) and journal impact factor (JIF)-weighted journal articles (JIFJOUR), also excluding journal self-citations (JIFJOURS), as dependent variables to assess the impact of the CORE grants. For the quality weighting, we use JIFs from 2018 as published by the WoS.

\section{CORE grants}

Information on research grants from the FNR under the CORE program was retrieved from the FNR's annual reports for the years 2001-2019. ${ }^{9}$ The annual reports contain next to a short description of the individual projects, information about the project domain, the principal investigator as well as the sponsored amount.

Figure 1 shows the number of projects granted and the average grant amount per project over time. The trendlines show that while the number of granted projects shows a slightly negative trend, the average grant amount increases slightly over time.

\footnotetext{
${ }^{9}$ Annual reports are available at the FNR homepage https:/www.fnr.lu/news/fnr-publications/. Note that the CORE program is run under this label since 2008. Before, the FNR had a very similar grant program with a different name in place but the same purpose, i.e. distributing the largest share of the research funds through project-based funding according to the national research priorities.
} 
Figure 1: Funding over time

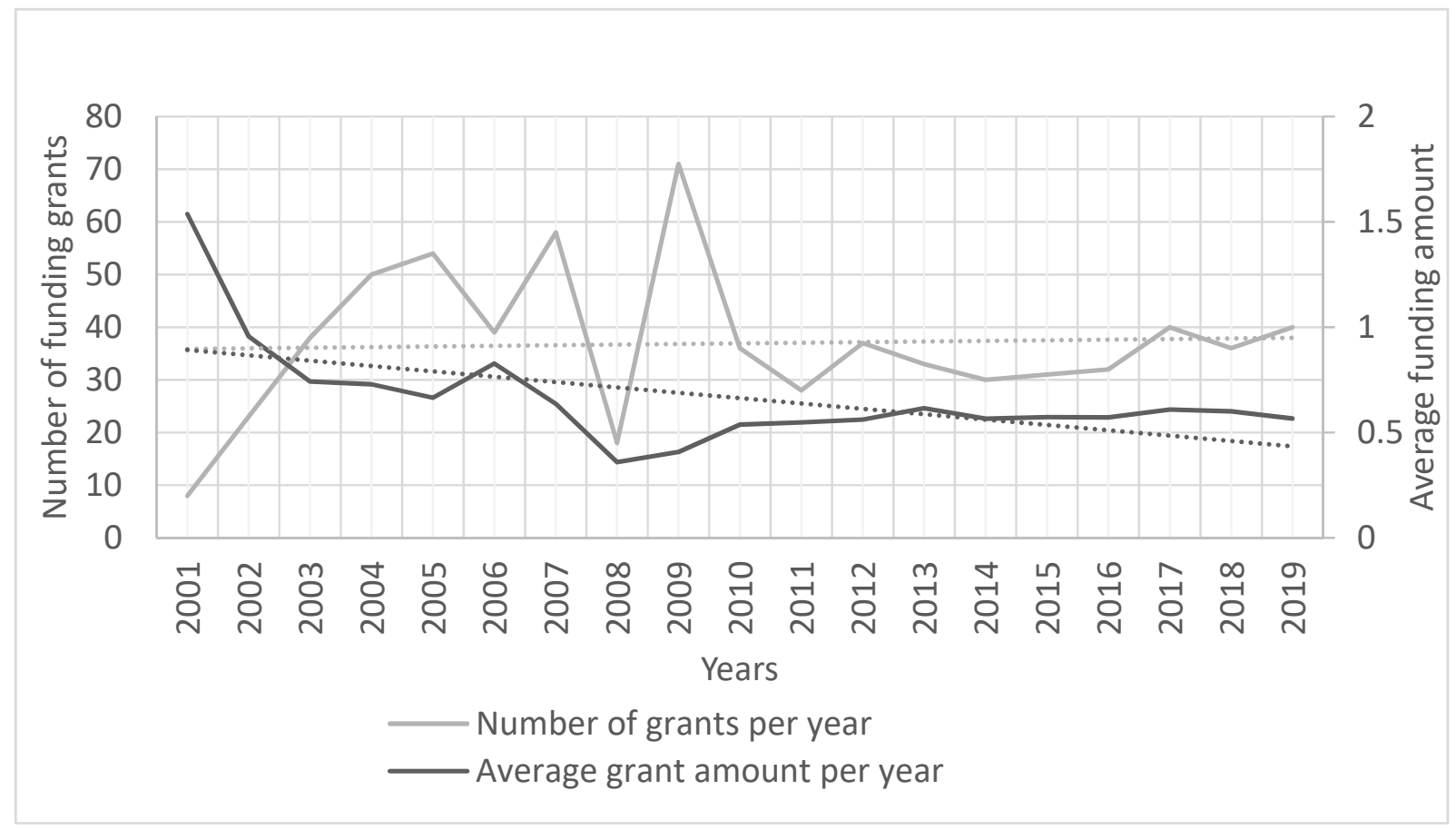

\section{Sample entry rule}

It needs to be defined when a professor enters the sample. We were able to retrieve information about the year in which the professor obtained her $\mathrm{PhD}$ for $77 \%$ of the university professors in our sample. For each professor who has at least one publication in a scientific journal or conference proceeding covered by the WoS, we observe the year of the first publication. Our entry rule is defined as follows: a professor enters the sample in the year of the $\mathrm{PhD}$ if the year of the $\mathrm{PhD}$ is observed and if the professor did not publish in earlier years. If the year of the $\mathrm{PhD}$ is unknown the professor enters the sample with the year of the first publication. If the year of the $\mathrm{PhD}$ is known and the professor published in earlier years, she enters the sample in the year of the first publication.

One might be concerned that the so-defined entry rule leaves us with too many observations per professors before the researchers joined the University of Luxembourg, i.e. when they were 
affiliated with a university outside of Luxembourg and, hence, were not eligible to apply for a CORE grant. In response to this concern, we present a robustness check that defines entry as the year in which the university professor joined the University of Luxembourg. A second robustness check which is available upon request sets the earliest possible year of sample entry to 1998 and confirms our results.

\section{Descriptive statistics}

From the initial 230 professors, 16 were dropped because they had no publication output retrievable from the WoS. An additional professor who joined the University of Luxembourg recently was dropped because only one year of observation was available so that this researcher could not be used for the panel data regressions. Our final sample, hence, consists of 213 university professors, $44 \%$ of which received at least one grant under the CORE program of the FNR. This corresponds to 1550 observations for grant recipients and 3132 observations for their colleagues. Our data spans a time frame of 45 years since the most senior professor had his first publication in 1976. On average, we have 21 yearly observations per professor. The most recent professor at the University of Luxembourg in our sample is observed for three consecutive years.

Table 1 shows descriptive statistics. It appears that CORE grant recipients are more productive than their colleagues at the University of Luxembourg who never received a CORE grant. This holds for journal publications (JOUR) and proceedings (PROC) and their sum (PUB), also if coauthor weighted (CJOUR and CPROC) and weighted by JIF (JIFJOUR and JIFJOURS).

Furthermore, Table 1 shows that FNR grant recipients received significantly more research grants in the past than their colleagues, that they have a higher stock of scientific publications and proceedings (both calculated with a depreciation rate of $15 \%$ ) and are more likely to be full 
professors. The variable that indicates the time to start or time since the start at the University of Luxembourg shows that the grant recipients are observed in more years before they joined the University of Luxembourg. Lastly, the descriptive statistics show that the share of grantees is relatively low in the Faculty of Law, Economics and Finance and the Faculty of Humanities, Education and Social Sciences as compared to the other university departments.

Table 1: Descriptive statistics

\begin{tabular}{|c|c|c|c|c|c|}
\hline \multirow[b]{2}{*}{ Variables } & \multicolumn{2}{|c|}{ Grant recipients } & \multicolumn{3}{|c|}{ Control group } \\
\hline & mean & std. err. & mean & std. err. & test \\
\hline journal articles + proceedings (PUB) & 2.96 & 1.22 & 1.66 & 0.07 & $* * *$ \\
\hline proceedings (PROC) & 0.92 & 0.07 & 0.24 & 0.02 & $* * *$ \\
\hline journal articles (JOUR) & 2.04 & 0.09 & 1.42 & 3.55 & $* * *$ \\
\hline co-author weighted proceedings (CPROC) & 0.29 & 0.02 & 0.08 & 0.01 & ** \\
\hline co-author weighted journal articles (CJOUR) & 0.65 & 0.03 & 0.57 & 0.03 & $* * *$ \\
\hline JIF weighted journal articles (JIFJOUR) & 3.90 & 0.23 & 2.55 & 0.18 & $* * *$ \\
\hline $\begin{array}{l}\text { JIF weighted journal articles without journal self-citations } \\
\text { (JIFJOURS) }\end{array}$ & 3.54 & 0.21 & 2.29 & 0.16 & $* * *$ \\
\hline number of previous grants $(>30.000 \mathrm{EU} / / \mathrm{R})$ & 1.88 & 0.13 & 0.60 & 0.03 & $* * *$ \\
\hline stock of journal articles (JSTOCK) & 7.51 & 0.20 & 4.81 & 0.13 & $* * *$ \\
\hline stock of proceedings (PSTOCK) & 3.34 & 0.17 & 0.86 & 0.06 & $* * *$ \\
\hline full professor & 0.76 & 0.01 & 0.58 & 0.01 & $* * *$ \\
\hline associate professor & 0.15 & 0.01 & 0.32 & 0.01 & $* * *$ \\
\hline assistant professor & 0.09 & 0.01 & 0.11 & 0.01 & * \\
\hline career age & 7.73 & 0.31 & 8.21 & 0.21 & \\
\hline time to/since start at the University of Luxembourg & -2.43 & 0.25 & -1.83 & 0.17 & $* *$ \\
\hline Child & 0.08 & 0.01 & 0.07 & 0.00 & \\
\hline Luxembourg Centre for Contemporary and Digital History & 0.05 & 0.01 & 0.03 & 0.00 & $* * *$ \\
\hline Faculty of Law, Economics and Finance & 0.11 & 0.01 & 0.24 & 0.01 & *** \\
\hline Faculty of Humanities, Education and Social Sciences & 0.25 & 0.01 & 0.34 & 0.01 & $* * *$ \\
\hline Faculty of Science, Technology and Medicine & 0.51 & 0.01 & 0.35 & 0.01 & $* * *$ \\
\hline Luxembourg Centre for Systems Biomedicine & 0.03 & 0.00 & 0.01 & 0.00 & $* * *$ \\
\hline $\begin{array}{l}\text { Interdisciplinary Centre for Security, Interdisciplinarity and } \\
\text { Trust }\end{array}$ & 0.05 & 0.01 & 0.03 & 0.00 & $* * *$ \\
\hline
\end{tabular}


Table 2 shows that the grant recipients are more productive in the six years following the grant receipt than in other years regarding all scientific output measures. This suggests that the CORE grants stimulate research productivity and quality temporarily.

Table 2: Scientific output by grant recipients

\begin{tabular}{|c|c|c|c|c|c|}
\hline & mean & std.err. & mean & std.err. & t-test \\
\hline PUB & 5.11 & 0.31 & 2.05 & 0.10 & $* * *$ \\
\hline PROC & 1.76 & 1.81 & 0.56 & 0.05 & $* * *$ \\
\hline JOUR & 3.35 & 0.20 & 1.49 & 0.08 & $* * *$ \\
\hline CPROC & 0.49 & 0.05 & 0.20 & 0.02 & $* * *$ \\
\hline CJOUR & 0.99 & 0.07 & 0.51 & 0.03 & $* * *$ \\
\hline JIFJOUR & 6.30 & 0.55 & 2.87 & 0.22 & $* * *$ \\
\hline JIFJOURS & 5.72 & 0.50 & 2.61 & 0.20 & $* * *$ \\
\hline
\end{tabular}

$* * *, * *, *$ indicate statistical significance at the $1 \%, 5 \%, 10 \%$ level.

\section{EMPIRICAL STRATEGY AND RESULTS}

\section{Empirical Strategy}

Our empirical analysis compares professors at the University of Luxembourg which are recipients of at least one CORE grant with researchers at the same institution who did not receive this specific grant. We conduct difference-in-difference analyses investigating changes of the university professors' scientific output in response to the grant. In a first analysis, we use all university professors at the University of Luxembourg which did not receive a CORE grant as control group. They work in the same environment so that they have the same conditions for conducting research and are affected by the same changes to these conditions over time. They are also exposed to the same research opportunities as they work on similar topics. Our empirical model reads:

$$
P U B_{i t}=\mathrm{f}\left(\beta_{0}+\beta_{1} * P O S T_{i t}+\delta_{i}+\gamma_{t}\right),
$$


Where $P U B_{i t}$ represents the sum of journal publications and proceedings. As outlined in the previous section we use different dependent variables that account for co-authorship and journal impact factors. The impact of the grant is captured by the coefficient $\beta_{l}$ of the variable POST $T_{i t}$. $P O S T_{i t}$ is a dummy variable that takes the value one for grant recipients in the six years following the grant application. Although the duration of the grant is typically shorter with about three years, we include the post-grant years to account for a publication lag. $\delta_{i}$ is a professor-specific fixed effect which captures time invariant characteristics such as talent and a "taste" for science (Stern, 2004). Note that a dummy variable that distinguishes grant recipients from other professors gets absorbed into the professor fixed effects. $\gamma_{i}$ depicts a full set of time variables. We estimate model (1) using fixed effects poisson models.

One might wonder whether using all professors employed at the University of Luxembourg as control group is too broad to identify the grant effects as this control group includes researchers whose productivity and chance to get a grant can be much lower than that of the funded professors. Therefore, we draw a second control group consisting of only the most similar university professor for each university professor in the treatment group. To determine the socalled nearest neighbour, we estimate the propensity to receive a grant. The control variables for this estimation are: the professor's research unit, the position of the professor (assistant, associate of full professor), the number of previous grants larger than 30.000 EUR that the professor acquired, her career age, the JIF-weighted publication stock, the stock of conference proceedings, the time that she spent at the University of Luxembourg, the number of children that the professor has as well as a set of year dummies. Based on the propensity score obtained, the nearest neighbour is chosen as the professor with the most similar likelihood to receive a 
grant who has not received one. ${ }^{10}$ Since we have a panel dataset, we chose the most similar observation for a non-treated professor in the year of the grant receipt (for recipients of multiple grants we use the best match in any year of a grant receipt, see also footnotes 9 and 10 for more information) and add all further observations available for the professor to the matched sample. We then re-estimate model (1) for the matched sample and conduct a number of robustness checks.

\section{Main results}

We start with a DiD analysis using the full sample of university professors as control group estimating model (1). Table 3 shows the results.

Table 3: Main results

\begin{tabular}{llllll}
\hline & 1 & 2 & 3 & 4 & 5 \\
\hline dep var & PUB & PROC & JOUR & CPROC & CJOUR \\
\hline & coeff. & coeff. & coeff. & coeff. & coeff. \\
& std. dev. & std. dev. & std. dev. & std. dev. & std. dev. \\
\hline post & $0.27 * * *$ & $0.48^{* * *}$ & $0.18^{* * *}$ & $0.36^{* * *}$ & $0.21^{* * *}$ \\
& $(0.04)$ & $(0.07)$ & $(0.04)$ & $(0.12)$ & $(0.07)$ \\
\hline $\mathrm{N}$ & 4682 & 2753 & 4606 & 2753 & 4606 \\
11 & -7464.39 & -2052.04 & -6658.00 & -942.91 & -3656.75 \\
\hline$* * *, * *, *$ indicate & statistical significance at the $1 \%, 5 \%, 10 \%$ level. Time dummies are included, but not reported.
\end{tabular}

Models 1-5 show that there is a positive significant effect for the six years following the receipt of the grant on the researchers' scientific output. The total number of publications increases by $31 \%(=\exp (0.27)-1)($ see model 1$)$. The number of proceedings increases by $62 \%(=\exp (.48)-1)$

${ }^{10}$ The nearest neighbour is chosen based on the Mahalanobis distance.

$$
M D_{i j}=\left(Z_{j}-Z_{i}\right)^{\prime} \Omega^{-1}\left(Z_{j}-Z_{i}\right)
$$

In our case, $Z$ contains the estimated propensity score. $\Omega$ is the empirical covariance matrix of the matching arguments based on the sample of potential controls. 
(model 2$)^{11}$ whereas journal publications (model 3 ) increase by $20 \%$ in the six years following the grant. Models 4 and 5 show the results for proceedings and publications weighted by coauthors. The results are very similar to the previous models with a lower estimated effect for proceedings and a higher estimated effect for journal publications.

Unreported results with the post grant period split into two periods show that proceedings which are meant to disseminate research results in a speedy manner start to appear in the first three years after the grant receipt, while journal publications appear after three years.

\section{Matched sample}

Here, we show the results for our matched sample which includes the grant recipients as well as their nearest neighbours in the grant year, i.e. the professors at the University of Luxembourg that never received a CORE grant with the most similar profile in the grant year as chosen by a propensity score estimate which is presented in Table 11 in the Appendix. Table 4 shows that the results are very similar the first results for the larger control group with slightly smaller estimated coefficients. ${ }^{12,13}$

\footnotetext{
${ }^{11}$ Note that the sample size for the regressions for publications in conference proceedings is smaller than for the other dependent variables. This is the case because some research fields such as for instance economics do not have the tradition to publish in conference proceedings. Researchers in those fields often do not have a single publication in a conference proceeding and can, hence, not be taken into consideration for fixed effects regressions. The same reason accounts for the different number of observations for model 3 with publications as dependent variable and model 1 with the total number of publications as dependent variable.

${ }^{12}$ The results presented in the paper use all nearest neighbors without using a cut-off point that defines a maximum distance tolerated between the treated observation and the nearest neighbor. For this sample, the mean absolute difference between the treated and the control research in terms of their propensity score is very small with 0.0041 . All observations in the matched sample fulfill the common support assumption. 682 observation in the potential control group did not fulfill this assumption and were not used for construction of the matched sample. To further check the balancedness of our matched sample, we re-ran the probit model for the matched sample, finding no significant difference for treated observations and controls. The results are available upon request.

Robustness checks using a cut-off point of 0.01 for the maximum distance allowed between treated observation and control observation confirm our results presented in Table 4, but also the long-term effects presented in the right panel of Table 9. The results are available upon request.

${ }^{13}$ As there is no optimal way of choosing matches for researchers which receive more than one CORE grant, we did a robustness check where we exclude multiple grant recipients. Here, we exclude any researcher that received more than one CORE grant or any other significant grant during the sample period. The results presented in Table 4 and
} 
Table 4: Matched sample

\begin{tabular}{llllll}
\hline & 1 & 2 & 3 & 4 & 5 \\
\hline dep var & PUB & PROC & JOUR & CPROC & CJOUR \\
\hline \multirow{2}{*}{ post } & coeff. & coeff. & coeff. & coeff. & coeff. \\
& std. dev. & std. dev. & std. dev. & std. dev. & std. dev. \\
\hline $\mathrm{N}$ & $0.25^{* * *}$ & $0.44 * * *$ & $0.15^{* * *}$ & $0.30^{* *}$ & $0.17^{* *}$ \\
11 & $(0.04)$ & $(0.07)$ & $(0.04)$ & $(0.13)$ & $(0.08)$ \\
\hline$* * *, * *, *$ indicate & -4878.31 & 1926 & 2834 & 1926 & 2834 \\
& 2856 & -1585.84 & -4249.27 & -708.70 & -2223.31 \\
\hline
\end{tabular}

It is crucial that the treatment and control group follow the same pre-treatment trend in order to derive a causal effect from DiD estimations. Figure 2 shows that this is the case for the matched sample. ${ }^{14}$ Figure 2 further suggests that the productivity increase for the grantees starts in the year prior to the grant relative to the control group. The productivity of the grant recipients begins to decline about five years after the grant receipt.

The increase in publications in the year before the grant receipt, i.e. when the researcher prepares the proposal, is an interesting finding. To get an idea what causes this effect we conducted 10 interviews with randomly selected principal investigators. We confronted the principal investigators with the finding and asked them to comment on the potential reason. Five of the interview partners (two from social sciences, two from biomedical sciences and one from computer sciences) said that one needs to show expertise in the narrowly defined topic area for which one applies for a grant. Pre-grant publications on the grant topic or closely related topics are from their point of view important for increasing the chances of winning a grant. Another

\footnotetext{
the matched sample results of Table 9 hold and are available upon request. As explained above, for the regressions presented in this paper, we use the best match for the researcher with multiple grants found in any first year of a CORE grant.

${ }^{14}$ Note that it is not possible to investigate the pre-treatment trends for the full sample because there is no base year for the control group. A base year for the matched sample exists as the grant recipients are matched to the control group in the year of the grant receipt. This year is used as base year for treatment and control group.
} 
principal investigator from the field of computer science added that a grant forces the applicant to describe the project idea and tasks and that an applicant would not necessarily wait for a grant acceptance to start the research. This researcher could also imagine that a researcher who is working on a "hot topic" that finds high acceptance at journals is more likely to win a grant. The regression results combined with the interview insights suggests that the research productivity effects of the grant are for some researchers higher than the estimated effects if one includes the pre-application publication increase in the calculation.

\section{Figure 2: Parallel trends}

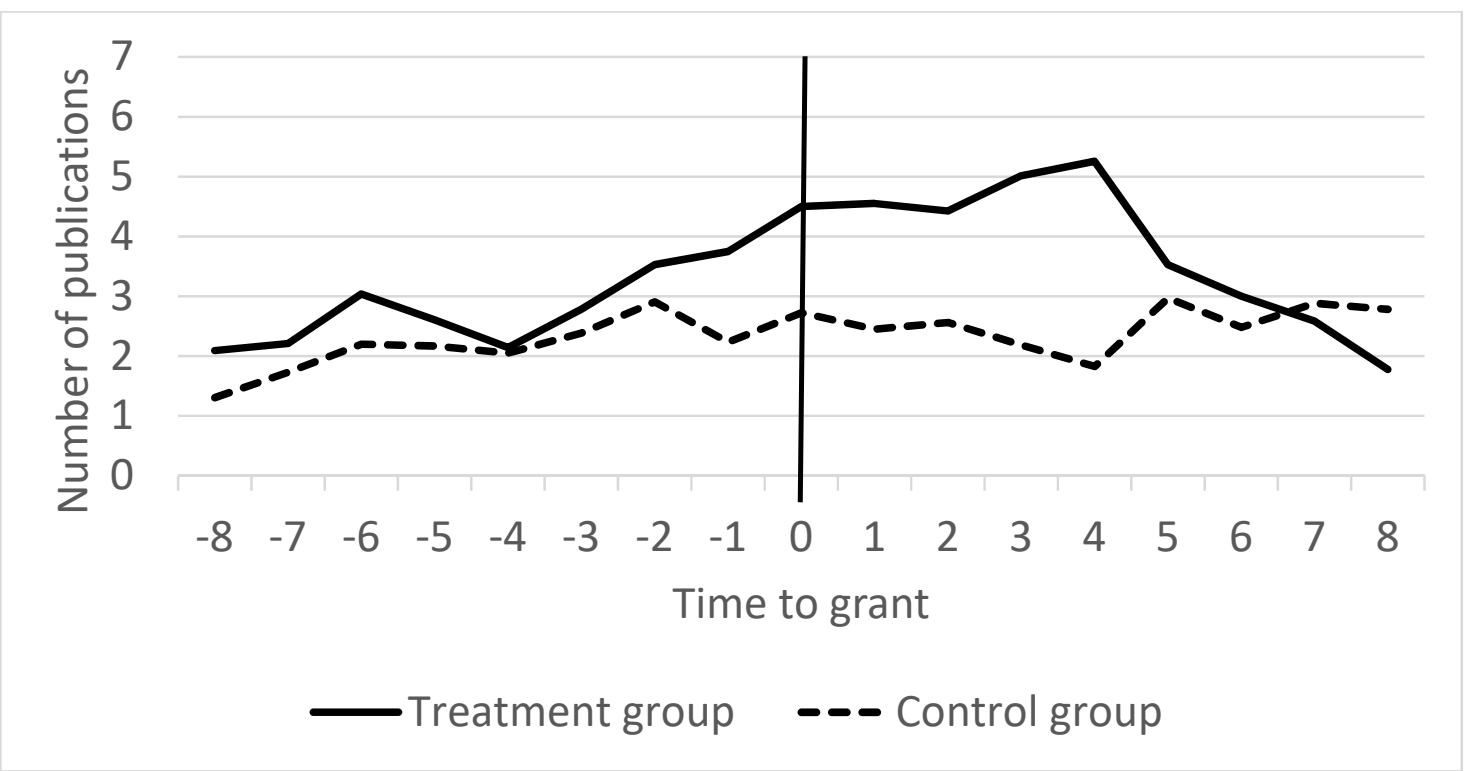

\section{Controlling for publication quality}

Table 5 shows the results when journal quality is considered by weighting each publication by the JIF. The results are very similar to the main results for the full and the matched sample. 
Table 5: Controlling for journal quality

\begin{tabular}{lllll}
\hline & 1 & 2 & 5 & 6 \\
\hline Sample & full sample & full sample & matched sample & matched sample \\
\hline dep var & JIFJOUR & JIFJOURS & JIFJOUR & JIFJOURS \\
\hline & coeff. & coeff. & coeff. & coeff. \\
& std. dev. & std. dev. & std. dev. & std. dev. \\
\hline Post & $0.21^{* * *}$ & $0.21^{* * *}$ & $0.20^{* * *}$ & $0.20^{* * *}$ \\
& $(0.03)$ & $(0.03)$ & $(0.03)$ & $(0.03)$ \\
\hline $\mathrm{N}$ & 3548 & 3548 & 2271 & 2271 \\
11 & -10905.51 & -10008.36 & -7065.57 & -6523.79 \\
\hline$* * *, * *, *$ indicate statistical significance at the $1 \%, 5 \%, 10 \%$ level. Time dummies are included, but not reported.
\end{tabular}

Figure 3 shows a plot of coefficients of a fixed effects poisson model for the matched sample where JIF weighted publications (JIFJOUR) are regressed on year dummies, a set of dummies showing the distance to the grant year (and for the control group the distance to the matching year) as well as a set of interaction terms of the distance dummies for the treated group. The coefficients are exponentiated and represent the incidence rate ratios. Confidence bands represent $95 \%$ confidence intervals.

Figure 3 shows an increase in quality-weighted publications over the project duration with the largest relative effect appearing in the fourth year after the receipt of the grant, which is the first year after most projects end. It further appears that the JIF-weighted publications are for some years after the grant above those of the control group with partially large confidence intervals. We investigate this effect further in the subsection "Further analysis". 
Figure 3: JIF-weighted publications relative to the control group

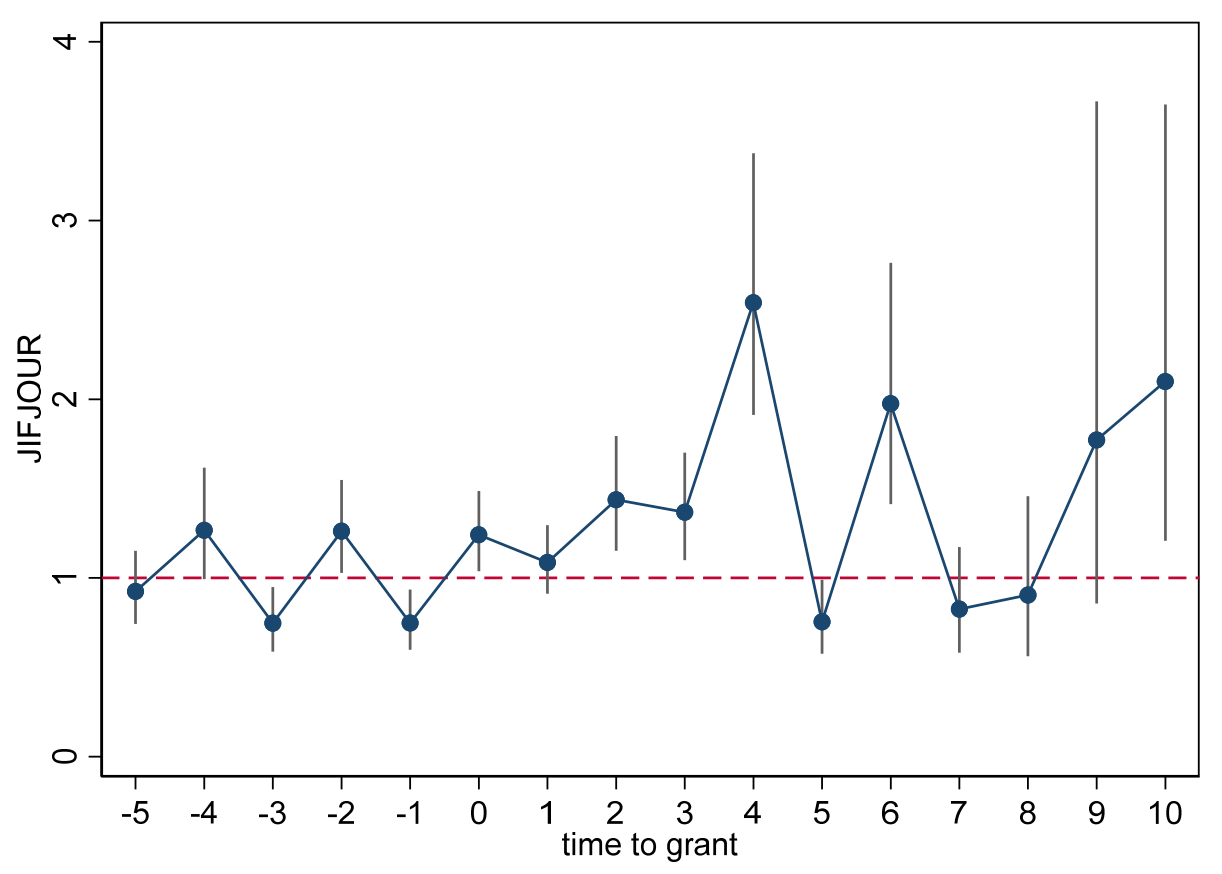

Robustness check I: Controlling for past publications

Table 6 shows that the results hold if we control for the past publication record of the university professors. We include the lagged stock of journal publications (JSTOCK) in the proceedings equation and the lagged stock of proceedings (PSTOCK) in the journal publication equation. If the dependent variable is weighted by the number of co-authors the stock variable is weighted by the number of co-authors as well (CJSTOCK and CPSTOCK). These variables proxy the amount of research ideas a professor has and vary over time. The results show that the past publication record has mostly a positive impact. The main result of a positive grant impact holds. 


\section{Table 6: Controlling for prior research productivity}

\begin{tabular}{|c|c|c|c|c|c|c|c|c|c|c|c|c|}
\hline & 1 & 2 & 3 & 4 & 5 & 6 & 7 & 8 & 9 & 10 & 11 & 12 \\
\hline Sample & full & full & full & full & full & full & matched & matched & matched & matched & matched & matched \\
\hline dep var & PROC & JOUR & CPROC & CJOUR & JIFJOUR & JIFJOURS & PROC & JOUR & CPROC & CJOUR & JIFJOUR & JIFJOURS \\
\hline & $\begin{array}{l}\text { coeff. } \\
\text { std. dev. }\end{array}$ & $\begin{array}{l}\text { coeff. } \\
\text { std. dev. }\end{array}$ & $\begin{array}{l}\text { coeff. } \\
\text { std. dev. }\end{array}$ & $\begin{array}{l}\text { coeff. } \\
\text { std. dev. }\end{array}$ & $\begin{array}{l}\text { coeff. } \\
\text { std. dev. }\end{array}$ & $\begin{array}{l}\text { coeff. } \\
\text { std. dev. }\end{array}$ & $\begin{array}{l}\text { coeff. } \\
\text { std. dev. }\end{array}$ & $\begin{array}{l}\text { coeff. } \\
\text { std. dev. }\end{array}$ & $\begin{array}{l}\text { coeff. } \\
\text { std. dev. }\end{array}$ & $\begin{array}{l}\text { coeff. } \\
\text { std. dev. }\end{array}$ & $\begin{array}{l}\text { coeff. } \\
\text { std. dev. }\end{array}$ & $\begin{array}{l}\text { coeff. } \\
\text { std. dev. }\end{array}$ \\
\hline post & $\begin{array}{l}0.43 * * * \\
(0.07)\end{array}$ & $\begin{array}{l}0.15 * * * \\
(0.04)\end{array}$ & $\begin{array}{l}0.35^{* * *} \\
(0.12)\end{array}$ & $\begin{array}{l}0.18 * * \\
(0.08)\end{array}$ & $\begin{array}{l}0.19 * * * \\
(0.03)\end{array}$ & $\begin{array}{l}0.20 * * * \\
(0.03)\end{array}$ & $\begin{array}{l}0.39 * * * \\
(0.07)\end{array}$ & $\begin{array}{l}0.12 * * * \\
(0.04)\end{array}$ & $\begin{array}{l}0.30^{* *} \\
(0.13)\end{array}$ & $\begin{array}{l}0.15^{*} \\
(0.08)\end{array}$ & $\begin{array}{l}0.19 * * * \\
(0.03)\end{array}$ & $\begin{array}{l}0.18 * * * \\
(0.03)\end{array}$ \\
\hline JSTOCK & $\begin{array}{l}0.01 * * * \\
(0.00)\end{array}$ & & & & & & $\begin{array}{l}0.01 * * * \\
(0.00)\end{array}$ & & & & & \\
\hline PSTOCK & & $\begin{array}{l}0.02 * * * \\
(0.00)\end{array}$ & & & $\begin{array}{l}0.01 * * * \\
(0.00)\end{array}$ & $\begin{array}{l}0.01 * * * \\
(0.00)\end{array}$ & & $\begin{array}{l}0.02 * * * \\
(0.00)\end{array}$ & & & $\begin{array}{l}0.02 * * * \\
(0.00)\end{array}$ & $\begin{array}{l}0.02 * * * \\
(0.00)\end{array}$ \\
\hline CJSTOCK & & & $\begin{array}{l}0.01 \\
(0.02)\end{array}$ & & & & & & $\begin{array}{l}0.05 * \\
(0.03)\end{array}$ & & & \\
\hline CPSTOCK & & & & $\begin{array}{l}0.10^{* * *} \\
(0.02)\end{array}$ & & & & & & $\begin{array}{l}0.10 * * * \\
(0.02)\end{array}$ & & \\
\hline $\mathrm{N}$ & 2575 & 4376 & 2575 & 4376 & 3376 & 3376 & 1844 & 2715 & 1844 & 2715 & 2175 & 2175 \\
\hline L1 & -1954.66 & -6353.87 & -895.08 & -3483.70 & -10431.20 & -9570.27 & -1520.66 & -4058.17 & -680.19 & -2132.63 & -6758.69 & -6238.74 \\
\hline
\end{tabular}

***,**,* indicate statistical significance at the $1 \%, 5 \%, 10 \%$ level. Time dummies are included, but not reported.

\section{Table 7: A different entry rule}

\begin{tabular}{|c|c|c|c|c|c|c|c|c|c|c|c|c|c|c|}
\hline & 1 & 2 & 3 & 4 & 5 & 6 & 7 & 8 & 9 & 10 & 11 & 12 & 13 & 14 \\
\hline sample & full & full & full & full & full & full & full & matched & matched & matched & matched & matched & matched & matched \\
\hline \multirow[t]{2}{*}{ dep var } & PUB & PROC & JOUR & CPROC & CJOUR & JIFJOUR & JIFJOURS & PUB & PROC & JOUR & CPROC & CJOUR & JIFJOUR & JIFJOURS \\
\hline & $\begin{array}{l}\text { coeff. } \\
\text { std. dev. }\end{array}$ & $\begin{array}{l}\text { coeff. } \\
\text { std. dev. }\end{array}$ & $\begin{array}{l}\text { coeff. } \\
\text { std. dev. }\end{array}$ & $\begin{array}{l}\text { coeff. } \\
\text { std. dev. }\end{array}$ & $\begin{array}{l}\text { coeff. } \\
\text { std. dev. }\end{array}$ & $\begin{array}{l}\text { coeff. } \\
\text { std. dev. }\end{array}$ & $\begin{array}{l}\text { coeff. } \\
\text { std. dev. }\end{array}$ & $\begin{array}{l}\text { coeff. } \\
\text { std. dev. }\end{array}$ & $\begin{array}{l}\text { coeff. } \\
\text { std. dev. }\end{array}$ & $\begin{array}{l}\text { coeff. } \\
\text { std. dev. }\end{array}$ & $\begin{array}{l}\text { coeff. } \\
\text { std. dev. }\end{array}$ & $\begin{array}{l}\text { coeff. } \\
\text { std. dev. }\end{array}$ & $\begin{array}{l}\text { coeff. } \\
\text { std. dev. }\end{array}$ & $\begin{array}{l}\text { coeff. } \\
\text { std. dev. }\end{array}$ \\
\hline post & $\begin{array}{l}0.31 * * * \\
(0.05)\end{array}$ & $\begin{array}{l}0.51^{* * * *} \\
(0.08)\end{array}$ & $\begin{array}{l}0.20 * * * \\
(0.06)\end{array}$ & $\begin{array}{l}0.42 * * * \\
(0.15)\end{array}$ & $\begin{array}{l}0.16^{*} \\
(0.10)\end{array}$ & $\begin{array}{l}0.27 * * * \\
(0.04)\end{array}$ & $\begin{array}{l}0.28 * * * \\
(0.04)\end{array}$ & $\begin{array}{l}0.30 * * * \\
(0.05)\end{array}$ & $\begin{array}{l}0.51^{* * *} \\
(0.08)\end{array}$ & $\begin{array}{l}0.19^{* * * *} \\
(0.06)\end{array}$ & $\begin{array}{l}0.43^{* * * *} \\
(0.15)\end{array}$ & $\begin{array}{l}0.14 \\
(0.10)\end{array}$ & $\begin{array}{l}0.26^{* * * *} \\
(0.04)\end{array}$ & $\begin{array}{l}0.26^{* * * *} \\
(0.04)\end{array}$ \\
\hline $\mathrm{N}$ & 2143 & 1083 & 2085 & 1083 & 2085 & 1515 & 1515 & 1312 & 822 & 1283 & 822 & 1283 & 999 & 999 \\
\hline $\mathrm{L} 1$ & -3439.32 & -999.72 & -3088.12 & -436.41 & -1594.35 & -4835.61 & -4446.35 & -2369.78 & -818.08 & -2087.05 & -350.79 & -1040.07 & -3376.91 & -3110.12 \\
\hline
\end{tabular}

$\begin{array}{lllllllll}\mathrm{Ll} & -3439.32 & -999.72 & -3088.12 & -436.41 & -1594.35 & -4835.61 & -4446.35 & -2369 .\end{array}$ 


\section{Robustness check III: Placebo test}

Table 8 shows a placebo test. Here, we pretend that the grant was received seven year prior to the actual grant receipt year. The variable $P O S T_{i t .}$ takes the value 1 for the six years following the placebo treatment year. For our DiD results to hold, we expect that there is no significant impact of the variable $P O S T_{i t}$ in this model. Table 8 shows that this is the case.

Table 8: Placebo test

\begin{tabular}{llllllll}
\hline & PUB & PROC & JOUR & CPROC & CJOUR & JIFJOUR & JIFJOURS \\
\hline & coeff. & coeff. & coeff. & coeff. & coeff. & coeff. & coeff. \\
& std. dev. & std. dev. & std. dev. & std. dev. & std. dev. & std. dev. & std. dev. \\
\hline \multirow{2}{*}{ post } & -0.14 & -0.18 & -0.14 & -0.02 & -0.06 & -0.05 & -0.04 \\
& $(0.09)$ & $(0.15)$ & $(0.11)$ & $(0.24)$ & $(0.18)$ & $(0.07)$ & $(0.08)$ \\
\hline $\mathrm{N}$ & 2856 & 1926 & 2834 & 1926 & 2834 & 2271 & 2271 \\
11 & -4899.59 & -1605.72 & -4253.96 & -711.57 & -2225.71 & -7084.36 & -6540.26 \\
\hline$* * *, * *, *$ indicate statistical significance at the $1 \%, 5 \%, 10 \%$ level. Time dummies are included, & but not reported.
\end{tabular}

Further analysis: Is the effect on scientific output long-lasting?

Figure 2 suggests that the effect of the grant on scientific output lasts for about five years. The results presented in Table 9 investigate this finding further by adding a dummy variable to the regression model which takes the value one for the grantees from the seventh post-grant year onwards. We find that for total publications, proceedings and journal publications, also if weighted by co-authors, the grant effect indeed lasts for not more than six years following the project grant. We, however, further find an effect on quality-weighted publications that goes beyond six years.

Investigating this effect further, Table 10 shows results for the matched sample where we distinguish between grant recipients which increase their impact factor during the six years after the grant as compared to the pre-grant period and others. The results show that those grantees 
that experience a publication quality increase in the post-grant years realize a long-lasting effect on the scientific quality of their articles (models 6 and 7).

There is no evidence for university professors who do not improve their JIF factor after the grant receipt to realize a long run effect. They, however, also increase their overall scientific output which is driven by an increase in the number of proceedings after the grant. Note that the negative effect of the grant on JIF weighted journal publications in models 13 and 14 occurs by definition of the subsample.

Simple t-tests suggest that the grant recipients who realize long-lasting quality effects are slightly older in terms of career age (14 versus 11 years), that they have a much higher publication stock (7.41 versus 2.39) and win a slightly higher amount of funding. Other factors such as previous grant applications or the professors' position at the university (full, associate or assistant professor) do not differ among both groups according to t-tests. Multivariate regression results from sample splits do not confirm systematic difference for these candidate characteristics though. 
Table 9: Long-lasting effects

\begin{tabular}{|c|c|c|c|c|c|c|c|c|c|c|c|c|c|c|}
\hline & 1 & 2 & 3 & 4 & 5 & 6 & 7 & 8 & 9 & 10 & 11 & 12 & 13 & 14 \\
\hline sample & full & full & full & full & full & full & full & matched & matched & matched & matched & matched & matched & matched \\
\hline dep var & PUB & PROC & JOUR & CPROC & CJOUR & JIFJOUR & JIFJOURS & PUB & PROC & JOUR & CPROC & CJOUR & JIFJOUR & JIFJOURS \\
\hline & $\begin{array}{l}\text { coeff. } \\
\text { std. dev. }\end{array}$ & $\begin{array}{l}\text { coeff. } \\
\text { std. dev. }\end{array}$ & $\begin{array}{l}\text { coeff. } \\
\text { std. dev. }\end{array}$ & $\begin{array}{l}\text { coeff. } \\
\text { std. dev. }\end{array}$ & $\begin{array}{l}\text { coeff. } \\
\text { std. dev. }\end{array}$ & $\begin{array}{l}\text { coeff. } \\
\text { std. dev. }\end{array}$ & $\begin{array}{l}\text { coeff. } \\
\text { std. dev. }\end{array}$ & $\begin{array}{l}\text { coeff. } \\
\text { std. dev. }\end{array}$ & $\begin{array}{l}\text { coeff. } \\
\text { std. dev. }\end{array}$ & $\begin{array}{l}\text { coeff. } \\
\text { std. dev. }\end{array}$ & $\begin{array}{l}\text { coeff. } \\
\text { std. dev. }\end{array}$ & $\begin{array}{l}\text { coeff. } \\
\text { std. dev. }\end{array}$ & $\begin{array}{l}\text { coeff. } \\
\text { std. dev. }\end{array}$ & $\begin{array}{l}\text { coeff. } \\
\text { std. dev. }\end{array}$ \\
\hline post & $\begin{array}{l}0.27 * * * \\
(0.04)\end{array}$ & $\begin{array}{l}0.46^{* * *} \\
(0.07)\end{array}$ & $\begin{array}{l}0.19 * * * \\
(0.04)\end{array}$ & $\begin{array}{l}0.32 * * * \\
(0.12)\end{array}$ & $\begin{array}{l}0.20 * * * \\
(0.08)\end{array}$ & $\begin{array}{l}0.23^{* * *} \\
(0.03)\end{array}$ & $\begin{array}{l}0.23^{* * *} \\
(0.03)\end{array}$ & $\begin{array}{l}0.24 * * * \\
(0.04)\end{array}$ & $\begin{array}{l}0.41^{* * *} \\
(0.07)\end{array}$ & $\begin{array}{l}0.15^{* * *} \\
(0.05)\end{array}$ & $\begin{array}{l}0.24 * \\
(0.13)\end{array}$ & $\begin{array}{l}0.15^{*} \\
(0.08)\end{array}$ & $\begin{array}{l}0.23^{* * *} \\
(0.03)\end{array}$ & $\begin{array}{l}0.22 * * * \\
(0.04)\end{array}$ \\
\hline $\begin{array}{l}\text { post } \\
(>6 \\
\text { years })\end{array}$ & $\begin{array}{l}-0.05 \\
(0.11) \\
\end{array}$ & $\begin{array}{l}-0.32 \\
(0.25) \\
\end{array}$ & $\begin{array}{l}0.05 \\
(0.12) \\
\end{array}$ & $\begin{array}{l}-0.65 \\
(0.51) \\
\end{array}$ & $\begin{array}{l}-0.16 \\
(0.25) \\
\end{array}$ & $\begin{array}{l}0.27 * * * \\
(0.09)\end{array}$ & $\begin{array}{l}0.26 * * * \\
(0.09)\end{array}$ & $\begin{array}{l}-0.09 \\
(0.11) \\
\end{array}$ & $\begin{array}{l}-0.38 \\
(0.25) \\
\end{array}$ & $\begin{array}{l}0.00 \\
(0.12) \\
\end{array}$ & $\begin{array}{l}-0.76 \\
(0.51)\end{array}$ & $\begin{array}{l}-0.24 \\
(0.25) \\
\end{array}$ & $\begin{array}{l}0.30^{* * *} \\
(0.09)\end{array}$ & $\begin{array}{l}0.28^{* * *} \\
(0.09)\end{array}$ \\
\hline $\mathrm{N}$ & 4682 & 2753 & 4606 & 2753 & 4606 & 3548 & 3548 & 2856 & 1926 & 2834 & 1926 & 2834 & 2271 & 2271 \\
\hline 11 & -7464.27 & -2051.11 & -6657.91 & -941.93 & -3656.54 & -10900.98 & -10004.45 & -4877.98 & -1584.53 & -4249.27 & -707.37 & -2222.81 & -7059.90 & -6519.25 \\
\hline
\end{tabular}

Table 10: Long-lasting effects: Quality increases through the funding are long-lasting

\begin{tabular}{|c|c|c|c|c|c|c|c|c|c|c|c|c|c|c|}
\hline & 1 & 2 & 3 & 4 & 5 & 6 & 7 & 8 & 9 & 10 & 11 & 12 & 13 & 14 \\
\hline sample & matched & matched & matched & matched & matched & matched & matched & matched & matched & matched & matched & matched & matched & matched \\
\hline $\begin{array}{l}\text { JIF } \\
\text { increase }\end{array}$ & yes & yes & yes & yes & yes & yes & yes & no & no & no & no & no & no & no \\
\hline \multirow[t]{2}{*}{ dep var } & PUB & PROC & JOUR & CPROC & CJOUR & JIFJOUR & JIFJOURS & PUB & PROC & JOUR & CPROC & CJOUR & JIFJOUR & JIFJOURS \\
\hline & $\begin{array}{l}\text { coeff. } \\
\text { std. dev. }\end{array}$ & $\begin{array}{l}\text { coeff. } \\
\text { std. dev. }\end{array}$ & $\begin{array}{l}\text { coeff. } \\
\text { std. dev. }\end{array}$ & $\begin{array}{l}\text { coeff. } \\
\text { std. dev. }\end{array}$ & $\begin{array}{l}\text { coeff. } \\
\text { std. dev. }\end{array}$ & $\begin{array}{l}\text { coeff. } \\
\text { std. dev. }\end{array}$ & $\begin{array}{l}\text { coeff. } \\
\text { std. dev. }\end{array}$ & $\begin{array}{l}\text { coeff. } \\
\text { std. dev. }\end{array}$ & $\begin{array}{l}\text { coeff. } \\
\text { std. dev. }\end{array}$ & $\begin{array}{l}\text { coeff. } \\
\text { std. dev. }\end{array}$ & $\begin{array}{l}\text { coeff. } \\
\text { std. dev. }\end{array}$ & $\begin{array}{l}\text { coeff. } \\
\text { std. dev. }\end{array}$ & $\begin{array}{l}\text { coeff. } \\
\text { std. dev. }\end{array}$ & $\begin{array}{l}\text { coeff. } \\
\text { std. dev. }\end{array}$ \\
\hline post & $\begin{array}{l}0.29 * * * \\
(0.04)\end{array}$ & $\begin{array}{l}0.38 * * * \\
(0.09)\end{array}$ & $\begin{array}{l}0.24 * * * \\
(0.05)\end{array}$ & $\begin{array}{l}0.27^{*} \\
(0.16)\end{array}$ & $\begin{array}{l}0.30 * * * \\
(0.09)\end{array}$ & $\begin{array}{l}0.39 * * * \\
(0.04)\end{array}$ & $\begin{array}{l}0.39 * * * \\
(0.04)\end{array}$ & $\begin{array}{l}0.26 * * * \\
(0.09)\end{array}$ & $\begin{array}{l}0.69 * * * \\
(0.15)\end{array}$ & $\begin{array}{l}-0.08 \\
(0.11)\end{array}$ & $\begin{array}{l}0.42 * \\
(0.25)\end{array}$ & $\begin{array}{l}-0.26 \\
(0.19)\end{array}$ & $\begin{array}{l}-0.72 * * * \\
(0.11)\end{array}$ & $\begin{array}{l}-0.72 * * * \\
(0.12)\end{array}$ \\
\hline $\begin{array}{l}\text { post } \\
\text { (>6 years) }\end{array}$ & $\begin{array}{l}0.08 \\
(0.12)\end{array}$ & $\begin{array}{l}-0.14 \\
(0.28)\end{array}$ & $\begin{array}{l}0.14 \\
(0.13)\end{array}$ & $\begin{array}{l}-0.42 \\
(0.61)\end{array}$ & $\begin{array}{l}-0.08 \\
(0.27) \\
\end{array}$ & $\begin{array}{l}0.53 * * * \\
(0.09)\end{array}$ & $\begin{array}{l}0.51 * * * \\
(0.10)\end{array}$ & $\begin{array}{l}-0.39 \\
(0.27) \\
\end{array}$ & $\begin{array}{l}-0.73 \\
(0.55)\end{array}$ & $\begin{array}{l}-0.23 \\
(0.32)\end{array}$ & $\begin{array}{l}-1.10 \\
(1.01)\end{array}$ & $\begin{array}{l}-0.98 \\
(0.66)\end{array}$ & $\begin{array}{l}-0.51 \\
(0.41)\end{array}$ & $\begin{array}{l}-0.57 \\
(0.44)\end{array}$ \\
\hline $\mathrm{N}$ & 2318 & 1638 & 2314 & 1638 & 2314 & 1987 & 1987 & 538 & 288 & 520 & 288 & 520 & 284 & 284 \\
\hline Ll & -3973.40 & -1189.42 & -3576.36 & -507.71 & -1879.03 & -6051.51 & -5585.92 & -801.26 & -355.79 & -592.91 & -173.64 & -306.55 & -673.16 & -629.14 \\
\hline
\end{tabular}


We conclude that our data analysis efforts are inconclusive regarding possible underlying mechanism based on observable characteristics behind the long-lasting quality effect that we find for some principal investigators. This is why we turned to interviews with 10 randomly chosen principal investigators. Their responses shed further light on possible reasons behind the effect. Interview partners were presented the finding and were asked to comment on it. There was an agreement among the interview partners across disciplines (psychology, physics, biomedical research, social sciences) that the CORE grant is especially for young and first-time grant applicants a chance to advance their careers as it can be the first opportunity for them to start building a team, manage a large research project, build or advance a network etc., therewith allowing them to take an important next step for their career. Two of the interview partners (biomedical research and computer science) specifically highlighted the size of the CORE grants that allows researchers to take a big step forward. Two researchers from biomedical research said that the grant size allows to conduct expensive experiments which lead to an important researcher advantage. One of these respondents added that therefore the CORE grant also leads to a higher visibility for the researcher through the published studies. Two other respondents (physics and biomedical research) highlighted a psychological effect of the grant leading to higher self-confidence for the awardee which can ultimately be reflected in long-lasting higher quality-weighted publication levels. Furthermore, one principal investigator (social sciences) noted that once a researcher reaches a certain publication quality level there is strong peer pressure to maintain or increase this publication quality level.

We conclude that the long-lasting effect for some principal investigators is most likely driven by the grant size that allows some researchers to take a next major career step, independent on their 
career age, to benefit from the grant regarding team building, managing large research projects, self-confidence, networking, and ultimately publications of higher quality.

\section{DISCUSSION}

Our investigation of Luxembourg's most important project-based research funding program for individual researchers (CORE) on the scientific output of university professors has revealed several interesting results. First, we find that the grants lead to additional scientific output of funded university professors in terms of conference proceedings and publications in scientific journals. These results hold for a matched sample, when co-authorship and journal quality is considered, under different sample entry rules and when we control for the university professors' past publication record. Our results suggest that a grant increases scientific output of the average sponsored university professor by $31 \%$, which corresponds to a $62 \%$ increase in proceedings and a $20 \%$ increase in publications in scientific journals. One should keep in mind that the productivity effects of the grant are for some researchers higher than the estimated effects if one includes a detected pre-application publication increase in the calculation. The estimated effects

alone correspond to almost one additional publication or equivalently 0.5 additional publications in conference proceedings and 0.4 additional journal publications. These effects lie within the spectrum of previous estimates for other research funding programs such as Arora and Gambardella (2005), Jacob and Lefgren (2011) and Benavente et al. (2012).

We further find that the positive effect of the funded professors' scientific output does not last longer than six years after the year of the grant receipt. Further analysis, however, shows that those grantees who realize a quality increase of their journal publications in the immediate postgrant years realize a long-lasting publication quality effect. This implies that the grant benefits 
those university professors' future career, the university as well as society through higher-quality science in the long run.

This finding is further interesting because it appears that the positive long-term effect on publication quality cannot be predicted by observable researcher characteristics. This finding has important implications for funding agencies as well as for scientific organizations hosting grant recipients. Funding agencies can design their programs such that a quality increase through the funded program is facilitated. The FNR already does so by requiring a mentoring function for first time CORE grant applicants. This is one possible way to aim at fostering a quality increase of the grant recipient's publication outcome. For host institutions, the finding suggests that grant recipients should be given the time and complementary resources to maximize the qualityweighted outcome of their funded project. Measures that could be employed include teaching reductions, complementary funding and (if applicable) guidance by senior researchers.

The finding of a long-lasting quality effect touches upon some further interesting issues. First, it suggests that some university professors are better able to make use of the grant money than others since not all professors manage to improve their long-term publication quality through the grant. Here, our focus on one university only is an advantage because we can exclude that the effect is caused by different research conditions at the host institution. Those professors that realize a quality improvement seem to be able to use the grant money as a kick-starter which catapults them onto a different scientific trajectory.

One might also wonder whether this effect is partially explained by the so-called Matthew effect in science (Merton, 1968). The Matthew effect describes a phenomenon by which scientists' status can become self-perpetuating. We believe that this is unlikely for our setting. Azoulay et al. (2014) find small and temporary limited evidence for a status effect for scientists becoming 
Howard Hughes Medical Institute (HHMI) investigators. Becoming HHMI investigator is a highly desired, highly visible scientific recognition which most likely results in a significant shift in researcher prominence. The grant program that we investigate - while important for spurring research - is not well known beyond national borders so that a potential status effect for the grantee is expected to be marginal and limited to the national peers.

Second, the result of a long-lasting quality effect suggests that the selection of the funded university professors by the funding agency is done in such a way that the potential of future development of the applicant as a scientist is considered. This is not necessarily the case for all research grant programs. The majority of research grant projects lists the scientific impact of the project (OECD, 2018b, Box 4.2) as well as the track record of the candidate as the most important success criteria (OECD, 2018, Figure 9), where scientific excellence is "often interpreted as both the scientific quality of the proposal itself and the quality of the scientists as judged by their track record" (OECD, 2018, p. 29). Our result suggests that it is important to distinguish between the quality of the proposal which might indicate a major career step to be taken by the applicant and the applicant herself since some applicants have the potential to use the grant to grow beyond the project duration.

An interesting avenue for future research would be to compare the individual research grants with collaborative research grants. As many other funding agencies, the FNR has increased its funding for collaborative projects, especially in collaboration with national partners in the private sectors. While these programs might benefit the local economy in the short run, they may have a small or even a negative effect on scientific research as a related study suggests (Czarnitzki et al., 
2009). ${ }^{15}$ National funding agencies should be careful when striking the balance between scientific excellence and support for the national economy. Scientific excellence is likely to have an important long-term effect for national economies which only becomes visible in later years since it takes time until important scientific inventions are commercialized, e.g. through university start-ups and partnerships with stakeholders in the private sector. Short-term partnerships between science and industry which are formed for a specific purpose and which are encouraged by increased funding opportunities for public-private partnerships are, in contrast, likely to also produce results with a short-term value in form of specific solutions for applied problems.

Our study is not free of limitations. First, it would be desirable to distinguish between grant applicants and their colleagues who never applied for a grant in order to further improve our control group and to be able to re-investigate the applicant effect reported by Ayoubi et al. (2019). Second, it would be interesting to investigate whether our results for the context of Luxembourg hold for other funding programs in other economies. Due to varying program designs across European countries and differences in national research landscapes and funding systems (Auranen and Nieminen, 2010, Lepori et al., 2007), we need a case-by-case evaluation and comparison of the results to learn about the generalizability of the findings.

\footnotetext{
${ }^{15}$ In their study, Czarnitzki et al. (2009) document that university professors' patents in cooperation with non-profit organizations complement publication quantity and quality, while patents which are assigned to corporations, i.e. the presumably more applied patents, are negatively related to publication quantity and quality. Similarly, Hottenrott and Lawson (2017) suggest that the effectiveness of public research grants is reduced by private research grants leading to reduced publication quantity and quality.
} 


\section{CONCLUSION}

This paper presents an investigation of the main research grant program for individual researchers in Luxembourg. With focus on university professors, we find that individual research grants increase the productivity of the grantees in terms of (quality and co-author weighted) journal publications and (co-author weighted) conference proceedings. An interesting result is that those professors who reach a higher publication quality level following the grant experience a longer-lasting quality effect. 


\section{REFERENCES}

Adams, J.D. (1990). Fundamental stocks of knowledge and productivity growth. Journal of Political Economy 98, 673-702.

Adams, J. and Z. Griliches (1998). Research productivity in a system of universities. Annals of INSEE 127-162.

Arora, A. and A. Gambardella (2005). The impact of NSF support for basic research in economics. Annales d'Economie et de Statistique 79 (80), 91-11.

Arrow, K. (1962). Economic welfare and the allocation of resources for invention. In R. R. Nelson (ed.), The Rate and Direction of Inventive Activity. Princeton University Press: Princeton.

Auranen, O. and M. Nieminen (2010). University research funding and publication performance - An international comparison. Research Policy 39, 822-834.

Ayoubi, C., M. Pezzoni and F. Visentin (2019). The important thing is not to win, it is to take part: what if scientists benefit from participating in research grant competition? Research Policy 48, 84-97.

Azoulay, P., J.S. Graff Zivin and G. Manso (2011). Incentives and creativity: evidence from the academic life sciences. RAND Journal of Economics 42 (3), 527-554.

Azoulay, P., T. Stuart and Y. Wang (2014). Matthew: effect or fable? Management Science 60 (1), 92-109.

Benavente, J.M., G. Crespi, L.F. Garone and A. Maffioli (2012). The Impact of National Research Funds: A Regression Discontinuity Approach to the Chilean FONDECYT. Research Policy 41, 1461-1475.

Chudnovsky, D., A. López, M.A. Rossi, and D. Ubfal (2008). Money for Science? The Impact of Research Grants on Academic Output. Fiscal Studies 29(1), 75-87.

Czarnitzki, D., W. Glänzel and K. Hussinger (2009). Heterogeneity of Patenting Activity and Its Implications for Scientific Research, Research Policy 38: 26-34.

Ganguli, I. (2017). Saving soviet science: the impact of grants when government R\&D funding disappears. American Economic Journal: Applied Economics 9(2), 165-201.

FNR (2018). FNR ANNUAL REPORT. Luxembourg.

FNR (2018-2021). FNR STRATEGY AND ACTION PLAN 2018-21. Luxembourg.

FNR (2019). Programme description. FNR CORE multi-annual thematic research programme. FNR, Luxembourg.

FNR (2020). Peer Review Guidelines. FNR CORE multi-annual thematic research programme. FNR, Luxembourg.

Hottenrott, H. and C. Lawson (2017). Fishing for Complementarities: Competitive Research Funding and Research Productivity. International Journal of Industrial Organization 51, $1-38$.

Jaffe, A. (1989). The real effects of academic research. American Economic Review 97(5), 957907.

Jacob, B.A. and L. Lefgren (2011). The impact of research grant funding on scientific productivity. Journal of Public Economics 95, 1168-1177. 
Lawson, C., A. Geuna and U. Finardi (2021). The Funding-Productivity-Gender Nexus in Science: A Multistage Analysis. Research Policy 50(3), 104182.

Lepori, B., P. van den Besselaar, M. Dinges, B. Poti, E. Reale, S. Slipersaeter, J. Theves and B. van der Meulen (2007), Comparing the evolution of national research policies: What patterns of change?, Science and Public Policy 34(6), 372-388.

Mansfield, E. (1991). Academic research and industrial innovation. Research Policy 20(1), 1- 12.

National Science Foundation (2012). Global summit on Merit Review. USA.

OECD (2016). OECD Science, Technology and Innovation Outlook 2016. OECD Publishing, Paris.

OECD (2018). Effective Operation of Competitive Research Funding Systems. OECD Science Technology and Industry. Policy Papers No. 57. Paris.

OECD (2018b). OECD Science, Technology and Innovation Outlook 2018: Adapting to Technological and Societal Disruption. OECD Publishing, Paris.

OECD (2019). OECD Economic Surveys - Luxembourg. Executive Summary. OECD Publishing, Paris

OECD (2020). Main Science and Technology Indicators. OECD Science Technology and Industry Database. OECD, Paris.

Patterson, D., L. Snyder, and J. Ullman (1999). Evaluating computer scientists and engineers for promotion and tenure. Best Practices Memo, Computing Research News. CRA Computing Research Association.

Payne, A. and A. Siow (2003). Does federal research funding increase university research output? Advances in Economics and Policy 3 (1).

Shamir, L. (2010). The effect of conference proceedings on the scholarly communication in computer science and engineering. Scholarly and Research Communication, September 201.

Stephan, P. (1996). The economics of science. Journal of Economic Literature 34 (3), 1199-1235.

Stern, S. (2004). Do scientists pay to be scientists. Management Science 50(6), 835-53.

Swedish Research Council (2019). The Swedish Research Barometer 2019. The Swedish Research System in International Comparison. Swedish Research Council Västra Järnvägsgatan 3.

The Research Council of Norway (2018). Numbers for 2018. The Research Council of Norway. Postboks 564, 1327 Lysaker. 


\section{APPENDIX}

Here, we present the results of the propensity score estimation. Table 11 shows the estimated coefficients from a probit model for the receipt of a CORE grant.

\section{Table 11: Probit Estimation for the receipt of a CORE grant}

\begin{tabular}{|c|c|c|c|}
\hline & coeff. & & std. err. \\
\hline number of previous grants ( $>30.000$ Eur) & 0.09 & $* * *$ & 0.02 \\
\hline JIF weighted JSTOCK & 0.00 & & $0.0)$ \\
\hline PSTOCK & 0.08 & $* * *$ & 0.02 \\
\hline full professor & 0.71 & $* *$ & 0.28 \\
\hline associate professor & 0.34 & & 0.29 \\
\hline career age & 0.20 & $* * *$ & 0.04 \\
\hline$(\text { career age })^{2}$ & -0.01 & $* * *$ & 0.00 \\
\hline time at the University of Luxembourg & 0.03 & $* *$ & 0.01 \\
\hline Children & -0.28 & & 0.22 \\
\hline Faculty of Law, Economics and Finance & -1.53 & $* * *$ & 0.36 \\
\hline Faculty of Humanities, Education and Social Sciences & -0.88 & $* * *$ & 0.34 \\
\hline Faculty of Science, Technology and Medicine & -0.82 & $* *$ & 0.34 \\
\hline Luxembourg Centre for Systems Biomedicine & -0.26 & & 0.77 \\
\hline Interdisciplinary Centre for Security, Interdisciplinarity and Trust & -0.18 & & 0.49 \\
\hline Constant & -9.07 & & 132.39 \\
\hline $\mathrm{LR} \mathrm{Chi}^{2}$ & & & 309.42 \\
\hline Pseudo $\mathrm{R}^{2}$ & & & 0.32 \\
\hline
\end{tabular}

The results show that the number of previous grants, the stock of proceedings, being a full professor, career age and (career age $)^{2}$ and the time at the University of Luxembourg have a positive, statistically significant impact on the receipt of a CORE grant. Note that we had missing information for some researchers considering the number of children and the entry into the University of Luxembourg. For these variables, a dummy was added to the empirical model which depicts missing information. 
Regarding the different research units of the University of Luxembourg, we use the Luxembourg Centre for Contemporary and Digital History $(\mathrm{CCDH})$ as benchmark. The results show that professors at the three faculties are less likely to receive a grant as compared to their peers at the research centres that are part of the University of Luxembourg. Interestingly, the stock of quality weighted journal publications (Arora and Gambardella, 2005, Azoulay et al., 2011) has no effect on the receipt of a CORE grant. If the quality weighting is omitted journal publications become statistically significant though.

We re-estimated the probit model for the matched observations and do not find significant coefficients which suggests that the matched sample is balanced.

We further re-estimated the probit model including a gender dummy. Slightly more than $22 \%$ of our researchers are female. Other than previous studies suggest (e.g. Lawson et al., 2021), we do not find a significant effect for the gender dummy on the likelihood of receiving a CORE grant. 
Download ZEW Discussion Papers from our ftp server:

http://ftp.zew.de/pub/zew-docs/dp/

or see:

https://www.ssrn.com/link/ZEW-Ctr-Euro-Econ-Research.html

https://ideas.repec.org/s/zbw/zewdip.html

$$
\text { // }
$$

IMPRINT

ZEW - Leibniz-Zentrum für Europäische Wirtschaftsforschung GmbH Mannheim

ZEW - Leibniz Centre for European

Economic Research

L 7,1 68161 Mannheim · Germany

Phone +49621 1235-01

info@zew.de·zew.de

Discussion Papers are intended to make results of ZEW research promptly available to other economists in order to encourage discussion and suggestions for revisions. The authors are solely responsible for the contents which do not necessarily represent the opinion of the ZEW. 